\title{
Insight \\ Methods for Developing Multiscale Participatory Scenarios: Insights from Southern Africa and Europe
}

\author{
$\underline{\text { Kasper Kok }}^{1}, \underline{\text { Reinette (Oonsie) Biggs }}^{2,3}$, and $\underline{\text { Monika Zurek }}^{4}$
}

\begin{abstract}
Scenario planning is increasingly recognized as a useful tool for exploring change in socialecological systems on decadal to centennial time horizons. In environmental decision making, scenario development tends to include participatory methods for engaging stakeholders and is conducted at multiple scales. This paper presents insights from participatory scenario development in two separate multiscale environmental assessments. We find that, to engage stakeholders at multiple scales, it is important that the issues explored at each scale be relevant and credible to stakeholders at that scale. An important trade-off exists between maintaining relevance to stakeholders at different scales and maintaining consistency across scales to allow for comparison of scenarios. Where downscaling methods are used to ensure consistency, there can be important consequences for (1) the diversity of scenario outcomes, (2) temporal mismatches in the storylines at different scales, and (3) power relationships among stakeholders at different scales. We suggest that development of participatory scenarios at multiple scales has a strong potential to contribute to environmental decision making, but it requires a substantial investment of time and resources to realize its full potential.
\end{abstract}

Key Words: Mediterranean; multiscale scenario; participation; scale; scenario; southern Africa

\section{INTRODUCTION}

Social, natural, and cultural systems are changing rapidly as the world globalizes. This creates large uncertainties, which gives consideration of the future new urgency and importance for policy makers, scientists, and citizens alike (Rotmans et al. 2000). Scenario planning is emerging as a method particularly well suited to the task of taking a longterm view and attempting to harmonize socioeconomic and environmental goals (Raskin et al. 1998). Increasingly, scenario initiatives encourage broad participation of scientists, policy makers, and citizens in exploring possible future development pathways (Kahane 1998). By using participatory methods, policy makers and other stakeholders can be directly involved in assessing possible futures and thus be better placed to help shape the future or adapt to changing conditions. At the same time, stakeholders at different scales have different perspectives, winners and losers may differ by scale, and different sets of issues and opportunities come into focus at different scales. Multiscale scenarios can take these issues into account and can thus add particular value when assessing interactions across scales and possible trade-offs.

The development of multiscale participatory scenarios is, however, a challenging process, and there are as yet few examples. This paper discusses insights from two recent experiences with the development of multiscale participatory scenarios. MedAction (http://www.icis.unimaas.nl/medaction ) was a project funded by the European Commission (EC) that focused on land degradation and desertification in Europe and the Mediterranean region. The Southern African Millennium Assessment (SAfMA) was one of approximately 30 subglobal assessments linked to the Millennium Ecosystem Assessment or MA (http://www.millenn iumassessment.org). The two studies were conducted independently between 2001 and 2004, and each study has been individually described. Based on discussions among the authors, there appeared to be striking similarities between the methodologies used and the informal lessons learned in the two projects. The aim of this paper is 
to synthesize and document these methods and lessons. We hope that our experiences may aid further work in this area.

\section{A NEW TOOL: MULTISCALE PARTICIPATORY SCENARIOS}

We define a scenario as a story about the future that can be told in both words and numbers, offering an internally consistent and plausible explanation of how events unfold over time (Gallopín et al. 1997, Raskin et al. 2002). Scenarios do not attempt to forecast or predict the future; instead, they envision several plausible pathways along which the future may develop and thereby account for critical uncertainties (Kahn and Weiner 1967). Scenarios are intended to widen perspectives and illuminate key issues that might otherwise be missed or dismissed. By incorporating nonlinearities, feedbacks, and surprises, scenarios offer sufficient flexibility to capture the complexity of the system.

The process of building scenarios asks questions about the future, as well as providing answers and guidance for action. Scenario developers usually start by determining a set of focal questions or issues in conjunction with their primary stakeholders. Next, storylines about the future are developed, quantified, and analyzed, usually iteratively (see, e. g., Alcamo 2001, Peterson et al. 2003). Today, scenario development is used in a variety of different contexts ranging from political decision making (Kahane 1998), to business planning (Wack 1985, Schwartz 1991), to global environmental assessments (Gallopín et al. 1997, IPCC 2002, UNEP 2002, Van Notten et al. 2003).

It has been suggested that the components of any complex system are structured hierarchically in space and time (Allen and Starr 1982, O'Neill 1988, Easterling and Kok 2003). Much of the groundbreaking work on scale in Earth system sciences can be attributed to ecologists with the conceptualization of the hierarchy theory. Much of the recent work on complex social-ecological systems emphasizes the need for understanding processes at multiple scales, particularly their interactions across scales (Peterson and Parker 1998, Walker et al. 2006, GLP 2005, Rotmans and Rothman 2003). There have been several recent attempts to develop multiscale scenarios to better understand processes at different scales and their interactions across scales. The foremost example includes the roughly 30 subglobal assessments linked to the MA (see Lebel et al. 2005). Other examples include Advanced Terrestrial Ecosystem Analysis and Modelling (ATEAM; Rounsevell et al. 2005) and EURURALIS (Westhoek et al. 2006), and this list will rapidly grow. The majority of these studies, however, did not use participatory processes.

A participatory process can be used to challenge the perceptions of those in authority and those at the grass-roots level, thereby influencing and changing attitudes and agendas. Planned and applied well, public participation can generate important and surprising insights that contribute to the design of policies better suited to serving the needs of those concerned (Patel et al. 2007). In this capacity, scenario planning becomes a vehicle for consensus building and problem solving (Wollenberg et al. 2000).

Scenario development is potentially a powerful tool to engage a variety of stakeholders. Not only can scenarios be developed without much technical skill, they can also be easily understood by scientists, policy makers, and lay people. Moreover, scenarios are flexible products that can incorporate a wealth of complex information from a variety of disciplines (see Van Asselt and Rijkens-Klomp 2002). In recent years, more attention has been paid to the value of incorporating participatory methods in scenario analyses. The specific application of participatory scenarios within a multiscale framework is gaining attention as well. Besides the examples given in this paper, PRELUDE (European Environment Agency 2006) and the fourth Global Environment Outlook (GEO) are worth mentioning.

\section{PROJECT BACKGROUND: CASE STUDIES}

We briefly introduce the two case studies before describing the similarities between them and the lessons we learned about designing and conducting multiscale assessments. The discussion in the remainder of the paper deals primarily with methodological scaling issues, as they were most challenging in both projects. We also discuss some insights from our experiences with regard to stakeholder involvement. 


\section{MedAction}

MedAction (2001-2004) aimed to develop an information and decision-support system on land degradation to assist decision makers at multiple levels. The study addressed desertification and mitigation measures at the European, Mediterranean, and local levels, and developed land-use change scenarios for each level. Figure 1 shows the main components and locations of the MedAction study.

The European-level scenarios were based on the earlier European Community-funded VISIONS project (1998-2001; see Rotmans et al. 2000, Van Asselt et al. 2005). VISIONS developed three European scenarios (2000-2050) and a set of independent regional scenarios for three case studies. These scenarios were subsequently combined to produce a set of integrated visions for European and regional development.

The scenarios in MedAction were all largely qualitative and took the form of narrative storylines; the local scenarios for the case study in Spain, however, were combined with a spatially explicit model (see Kok and Van Delden 2004). The objective of MedAction was to downscale regionallevel European scenarios to the local level, and to upscale the results of a series of local-level stakeholder workshops back to the Mediterranean and European levels. Consequently, developing and usng cross-scale scenario methods became pivotal. Scaling procedures predominantly dealt with constructing stories that were consistent across scales. Links between actual courses of events within scenarios were encouraged but were not always present in the final product. As a first step, the three European scenarios developed within the VISIONS project were enriched with specific information on a variety of sectors, most importantly agriculture and tourism, and factors such as water availability and land degradation that were not originally included. Three European scenarios were thus developed: Convulsive Change, in which climate change triggers droughts and floods; Big Is Beautiful, in which merger mania and a 40-country European Union fail to take social responsibility; and Knowledge Is King, in which the information and communications technology sector booms and leads to increased mobility and the formation of a European sunbelt. Scenarios were subsequently further enriched with national-level detail and downscaled to the Mediterranean level (see Kok et al. 2006a).
Using a variety of approaches, we developed local scenarios during two stakeholder workshops in each of the case study areas. During the first series of workshops we presented the main developments in the three Mediterranean scenarios to a group of 20 25 stakeholders and invited them to discuss the future of their region in light of these higher-level forces. We emphasized that, although these largescale external drivers were important, local scenarios should be based as much as possible on local circumstances. Local facilitators were trained to stimulate creative thinking. In a second series of workshops, we used a backcasting methodology in which stakeholders selected desirable end points and identified sets of short-term actions aimed at achieving these desired futures. Both workshops stimulated a critical evaluation of the key uncertainties and main developments in the Mediterranean scenarios. As a result, the majority of the local scenarios were indeed a mixture of highlevel developments and local specifics. Thus, applying strict downscaling methodologies facilitated comparison and upscaling across scales. The process and results of the scenario development activities within MedAction are described in detail in the literature (Kok et al. 2006a,b, Kok and Van Delden 2004, Patel et al. 2007) or can be found on the MedAction website.

\section{Southern Africa Millennium Ecosystem Assessment (SAfMA)}

The Millennium Ecosystem Assessment (MA) was a 4-yr international effort, carried out between 2001 and 2005, to provide decision makers with information on the consequences of ecosystem change for human well-being (Millennium Ecosystem Assessment 2005). The approach adopted by the MA focused on ecosystem services, including provisioning services such as for food and water, as well as regulating services such as flood mitigation, supporting services such as soil formation, and cultural services related to spiritual or aesthetic values. The MA comprised three major components: (1) an assessment of the current condition and trend in the supply of and demand for ecosystem services, (2) the development of scenarios of plausible future changes in the supply and demand of ecosystem services and the consequences for human well-being, and (3) an analysis of the types of responses that could be implemented to improve ecosystem management and thereby human well-being. 
Fig. 1. Simplified Program Evaluation and Review Technique (PERT) diagram of the main activities in MedAction (upper right) and scales for which multiscale scenarios were developed (lower left).

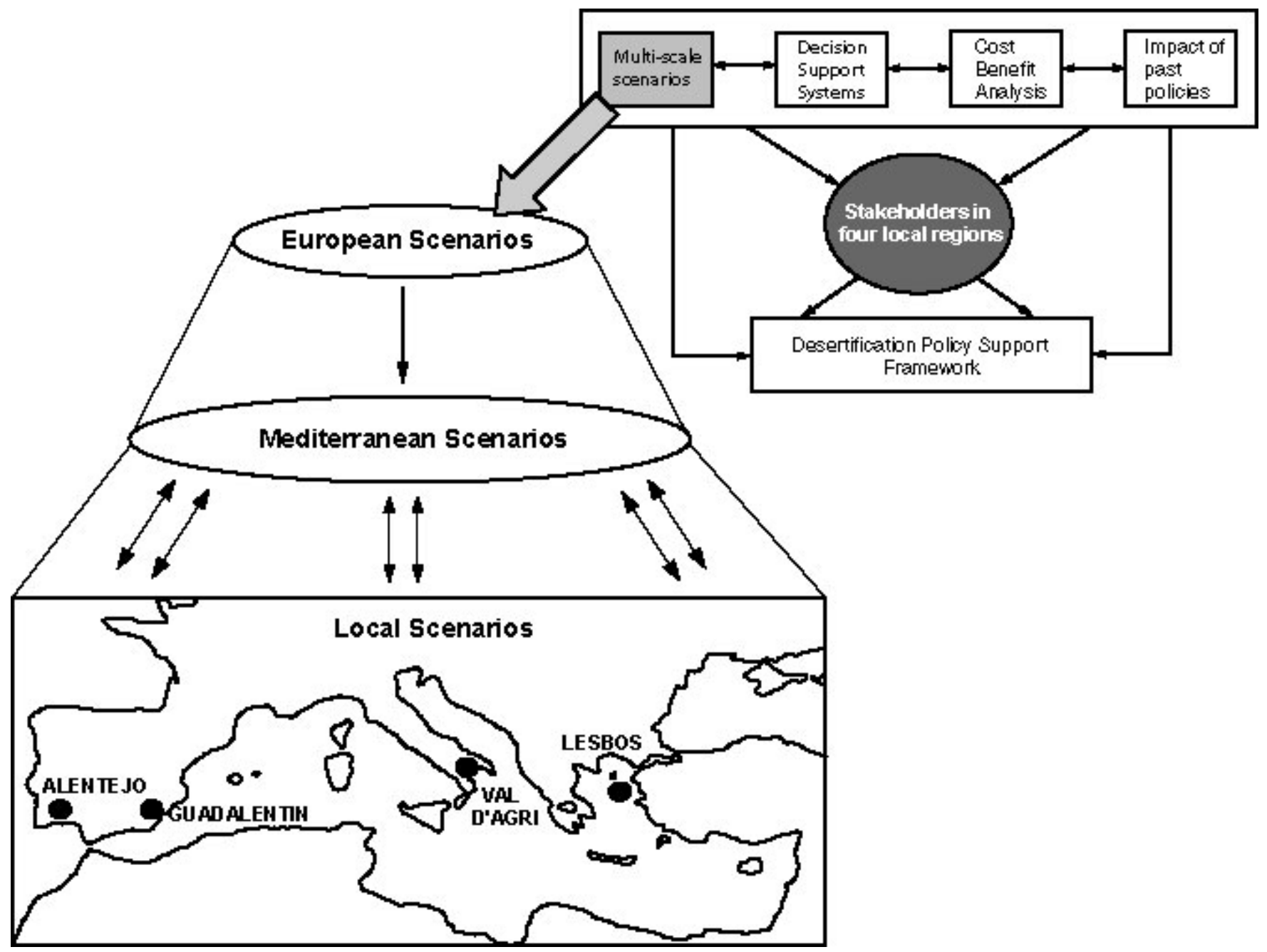

A novel feature of the MA was that it consisted of assessments at the global level as well as at regional and local levels. SAfMA consisted of a cluster of several subglobal assessments undertaken at three different spatial scales in southern Africa (Fig. 2; Biggs et al. 2004). Five local-scale assessments, each covering the area of a community or local authority, were nested within two basin-scale assessments. The basins were in turn nested within an assessment of the subequatorial continental region. Each SAfMA component study had its own assessment team, consisting of about five dedicated members, and a user advisory group of about 10 members who guided the assessors in determining what information users needed. All SAfMA studies assessed three core services, i.e., food, water, and services linked to biodiversity, as well as additional services of interest to the stakeholders at the particular site or scale.

At the global level, the MA developed four global storylines, which were linked to quantitative models. Initially, SAfMA had considered translating the MA global-scale scenarios down to regional, basin, and local levels to develop fully integrated, nested multiscale scenarios. This idea 
Fig. 2. The Southern Africa Millennium Ecosystem Assessment study area and its multiscale nested design. MA stands for Millennium Ecosystem Assessment, and SADC for Southern African Development Community.

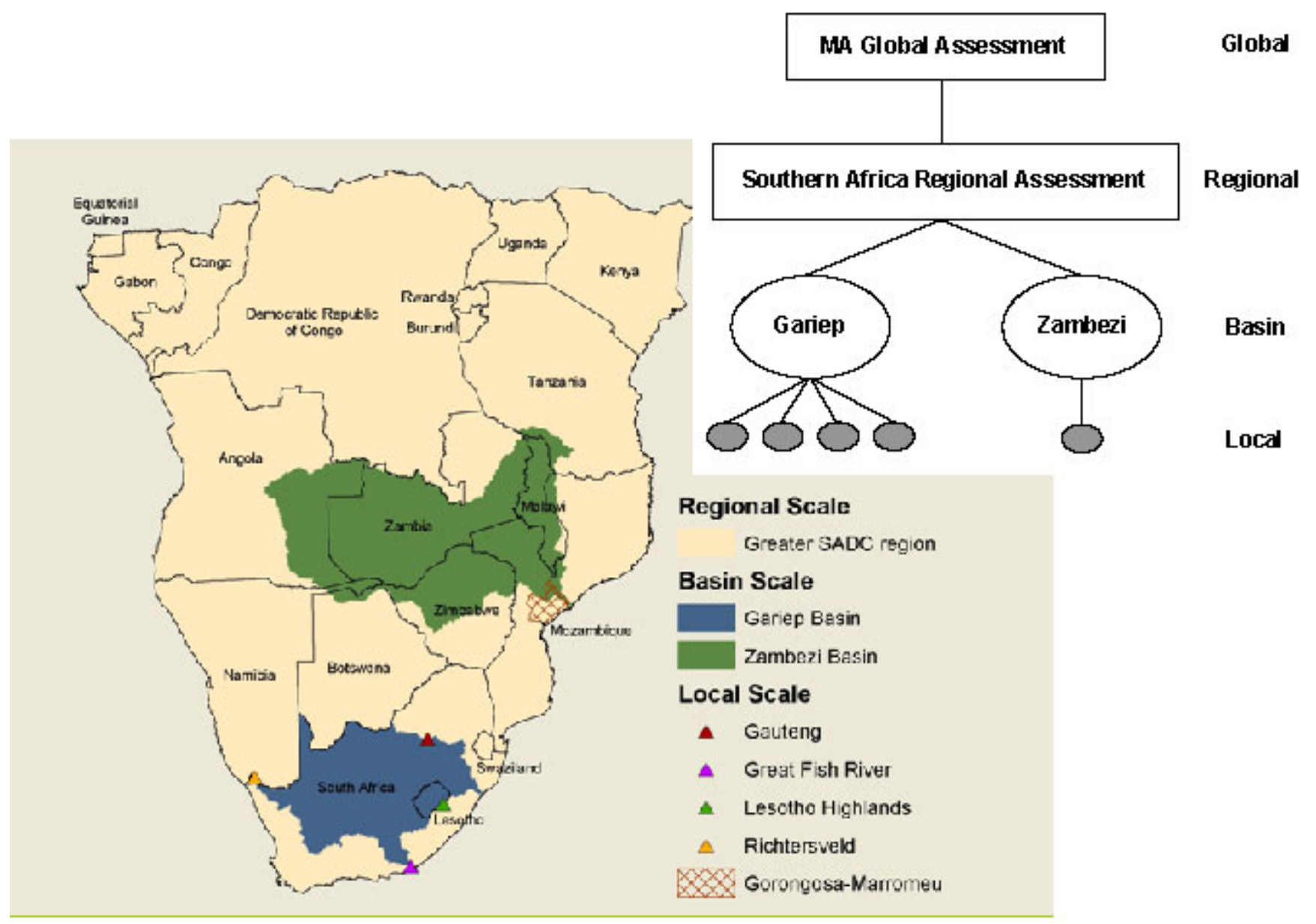

was abandoned for two reasons: (1) the MA global scenarios were not ready at the time SAfMA had to carry out its scenarios exercise, and (2) it was strongly felt by the SAfMA local-scale groups that such an approach would lead to top-down identification of major uncertainties and thus hold little relevance to their particular situations, in which other factors may be more important. To allow stakeholders the freedom to identify the factors they felt were most important at each scale, and to develop scenarios that were useful and made sense at each particular scale, it was decided that the substudy groups within SAfMA would construct their scenarios independently.
A diversity of scenario development methods was used in SAfMA. The storylines from four existing regional scenario studies were cross-tabulated against five scenario archetypes derived from the MA (see Scholes and Biggs 2004, Raskin et al. 2005). The key elements of the storylines corresponding to the archetypes Local Resources and Policy Reform, as well as elements from the New Partnership for Africa's Development (NEPAD 2001, 2002), were then synthesized using the MA conceptual framework (MA 2003) to create the two SAfMA regional-scale scenarios. The Gariep Basin assessment used four scenario archetypes, i.e., Fortress World, Market Forces, Local Resources, and Policy Reform, and explored 
their implications for ecosystem services and human well-being in the basin by means of a small expert workshop (Bohensky et al. 2004, Bohensky et al. 2006). The Zambezi Basin assessment based its scenarios on the Intergovernmental Panel on Climate Change Special Report on Emissions Scenarios (IPCC 2002) and used the International Futures Simulation models (Hughes 1999) to quantitatively explore scenarios of poverty, food insecurity, water, and energy.

At the local scale, the Gariep local livelihoods assessment identified the key drivers and their likely permutations to derive three qualitative storylines by means of an expert workshop. These scenarios were then converted into theatrical plays and acted out to the local communities to elicit feedback (Bohensky et al. 2004). In the GorongosaMarromeu assessment, two qualitative scenarios were developed in consultation with their user advisory group and presented to the community and other decision makers to explore how they would respond under the different scenarios (Lynam et al. 2004). Other than the Zambezi Basin scenarios, the SAfMA scenarios were all qualitative in nature. After completion, the scenarios developed at the different scales of SAfMA were related by crossclassification based on their major uncertainties (Table 1; see Biggs et al. 2004).

\section{Methodological similarities between the Southern Africa Millennium Ecosystem Assessment and MedAction}

The strong methodological analogies between SAfMA and MedAction form the backbone of this paper. Despite their independent design and execution, similar insights emerged on how carrying out such multiscale scenarios could be improved. We feel that these insights may provide valuable guidance to future multiscale scenario exercises. The key methodological similarities between SAfMA and MedAction that provide the basis for our shared insights are as follows:

- In both studies, work was carried out at three hierarchically nested scales, i.e., continental, national, and local, emphasizing slow processes at the broadest scale and fast processes at the local scale.
- The goal in both exercises was to aid decision makers at multiple scales. Each scale therefore had its own problem definition and group of experts and users.

- Scenarios at the broadest scale were adapted from existing published scenarios. Although the original work involved stakeholders in scenario development, the adaptation process in both SAfMA and MedAction was a desktop study.

- Scenarios at the intermediate level, i.e., Mediterranean in MedAction and basin-scale in SAfMA, were developed within the projects but without any active stakeholder involvement.

- Scenarios at the local level were developed using highly participatory methods, both during the development phase and to communicate results. Scenario workshops were the key method of involving stakeholders. Stakeholders included policy and decision makers, as well as community members and journalists.

- In both exercises, scenarios at all scales took the form of highly integrative but largely qualitative storylines. In specific instances, models were used to illustrate the quantitative consequences of scenarios, but they were not central to the methodology in either study.

The most significant methodological difference was the method used to link the scenarios developed at different scales. In SAfMA, scenarios were largely developed independently and linked afterwards based on similarities in the storylines. In MedAction, the use of iterative upscaling and downscaling processes ensured consistency in the scenarios at different scales. This difference provides the basis for several important insights with regard to the advantages and disadvantages of different options for linking across scales.

It goes without saying that the contextual differences are large. For example, local stakeholders in sub-Saharan Africa differ culturally, socially, and economically from those in the Northern Mediterranean. Such differences necessarily call for caution when comparing studies. However, it is largely because of the contextual differences in the two case studies that the overlap in the insights 
Table 1. Classification of the Millennium Ecosystem Assessment (MA) global scenarios, the South African Millennium Ecosystem Assessment (SAfMA) regional scenarios, the Gariep basin scenarios, and the Gariep local assessment scenarios into four scenario archetypes (Biggs et al. 2004).

\begin{tabular}{lcccc}
\hline \hline Scenario archetype & MA global & SAfMA regional & Gariep basin & Gariep local assessment \\
\hline Fortress World & Order from Strength & $\begin{array}{c}\text { African } \\
\text { Patchwork }\end{array}$ & $\begin{array}{c}\text { Fortress } \\
\text { World }\end{array}$ & Stagnation \\
Local Resources & Adapting Mosaic & $\ldots$ & Local Learning & $\ldots$ \\
Market Forces & $\begin{array}{c}\text { Global Orchestration } \\
\& \text { Technogarden }\end{array}$ & $\begin{array}{c}\text { African } \\
\text { Partnership }\end{array}$ & Market Forces & Green Engineering \\
Policy Reform & $\ldots$ & $\ldots$ & Policy Reform & Betterment \\
& $\ldots$ & & & \\
\hline
\end{tabular}

we gained struck us as worth highlighting. It suggests that these insights may be robust across a wide range of contextual settings for multiscale scenarios using methodologies similar to those used in our studies.

\section{INSIGHTS: MULTISCALE STAKEHOLDER PARTICIPATION}

In both MedAction and the Southern Africa Millennium Ecosystem Assessment (SAfMA), stakeholders were involved with the ultimate goal of providing guidance for action with a long-term perspective. The involvement of stakeholders at different scales showed some striking similarities across the two studies.

\section{Engaging stakeholders at different scales}

The choice of where to focus participatory exercises is primarily determined by the objective of the exercise. When the aim is to engage local-level stakeholders in processes initiated at higher levels and to increase the relevance of such initiatives, as in both the Millennium Ecosystem Assessment (MA) and MedAction, the focus will tend to be on engaging local-level stakeholders. Where the aim is primarily to influence national-level decision making, the focus will be on engaging stakeholders at this level (e.g., Galer 2004). In some cases it will be desirable to engage stakeholders to a similar extent at several scales.

In both SAfMA and MedAction, scenarios at the lower levels involved greater stakeholder participation than did scenarios at higher levels. In both studies, involving stakeholders, especially government officials, at the local level was believed to be easier and less costly than engaging stakeholders at higher levels. Unless initiated or authorized by the central government, it is often easier for a project to gain access to local-level government representatives than to representatives of national and supranational governance structures. Another consideration was that, in both SAfMA and MedAction, the recent studies that were drawn on to develop the higher-level scenarios had involved extensive stakeholder participation, therefore adequately capturing the stakeholder views at this scale. The literature indicates that it is possible to successfully engage stakeholders at the national or international level (e.g., Hisschemöller and Mol 2002). Within the framework of the Millennium Ecosystem Assessment there are several examples, of which the subglobal assessment in the Caribbean Sea, which deals with the collapse of fisheries in the area, is most illustrative. This example suggests that the engagement of higher-level stakeholders is greatly facilitated if a higher-level governing structure that 
engages diverse stakeholders already exists, as in the Caribbean.

The stakeholder selection procedure is crucial to the outcome of any participatory process. It has been suggested that four groups of stakeholders should be represented: policy makers, business representatives, citizens, and experts (Andersen and Jaeger 1999). Both MedAction and SAfMA aimed at a broader participation, also involving groups such as young people, poets, and free thinkers, and explicitly aiming to involve groups that are usually underrepresented. The variety was also maximized in terms of profession, gender, and age.

The process of engaging stakeholders at the local level was successful in both projects. Table 2 contains selected results from questionnaires that were handed out after the first and the second series of MedAction workshops. The majority of the stakeholders were clear on what was expected beforehand, they were satisfied with their own role in the group process, and they returned for the second workshop (for more details, see Patel et al. 2007).

\section{Perceptions at different scales}

A major difficulty in involving diverse stakeholders is the difference in epistemologies or knowledge systems and thus in the perceptions of different actors. The same words or concepts may be understood differently at different scales, between scientists and stakeholders, and among stakeholders. Some examples from our case studies are listed below.

\section{Land degradation}

In the Spanish and Italian case studies of MedAction, the word "territory" (territorio) is central to many of the discussions among stakeholders. It can be literally translated as "region" or "area," but this does not take account of the connotations of homeland or birthplace also associated with the word. English does not have a good equivalent and might overlook or underestimate a deeper connection to the land in the Mediterranean countries than was reflected in the European-level scenarios. Similar conclusions have been drawn by, e.g., Antrop (2000), who states that "the concepts of land and landscape are fundamentally different," and it is one of the fundamental assumptions of many recent articles in the journal Landscape and Urban Planning (http:// www.elsevier.com/locate/landurbplan. This provides an example of how a multiscale scenario exercise can facilitate better appreciation of differing values. However, if not dealt with carefully, local-scale values may be drowned out by the imposition of values associated with the higherlevel scenarios.

\section{Governance}

During the SAfMA pilot study, it was proposed that the effectiveness of central governance should be explored as a key uncertainty at all levels of the assessment. However, the local community assessments argued that, in their context, other uncertainties would be more important. As a result, it was decided to develop scenarios independently in the different SAfMA substudies, based on the key uncertainties identified in each study. In retrospect, however, the effectiveness of government was identified as a major uncertainty in every study at every scale. It was framed, however, in terms of government and the governing institutions at the scale of each particular study, rather than simply the national government. This ensured relevance and ownership of the scenarios by stakeholders at all scales.

\section{Scenario}

The scientific definition states that a scenario is a story, that is, a series of events leading to an end point. From the experiences of MedAction, it became clear that stakeholders struggled with exercises that set out to link shorter-term actions to long-term alternative visions. In part this was related to the perception of a scenario as a desirable end point or prediction rather than a story and a series of possible events. Clarifying what is meant by the word "scenario" is critical to successfully engaging stakeholders in a scenarios exercise and may require considerable effort and time.

In developing scenarios, particularly at different scales, it is of the utmost importance to identify and capture differences in values and perspectives. The perspective at any particular scale is not right or wrong. At different scales, different sets of issues and opportunities come into focus, and much of the value of a multiscale exercise lies in increasing awareness of such issues. A scenarios exercise 
Table 2. Selected results from the stakeholder questionnaires in Spain (Sp) and Italy (It), conducted after the first and second series of scenario workshops in MedAction.

\begin{tabular}{|c|c|c|c|c|c|c|}
\hline \multirow[t]{2}{*}{ Question } & \multicolumn{2}{|c|}{$\begin{array}{c}\text { Yes (Y) } \\
(\%)\end{array}$} & \multicolumn{2}{|c|}{$\begin{array}{c}\text { Relatively (R) } \\
(\%)\end{array}$} & \multicolumn{2}{|c|}{$\begin{array}{l}\text { No (N) } \\
(\%)\end{array}$} \\
\hline & It & $\mathrm{Sp}$ & It & $\mathrm{Sp}$ & It & $\mathrm{Sp}$ \\
\hline \multicolumn{7}{|l|}{ First workshop } \\
\hline Were you clear of the purpose of the workshop? $(\mathrm{Y} / \mathrm{R} / \mathrm{N})$ & 88 & 70 & 12 & 30 & $\ldots$ & $\ldots$ \\
\hline Did you feel that you could voice your opinion? $(\mathrm{Y} / \mathrm{N})$ & 100 & 100 & $\ldots$ & $\ldots$ & $\ldots$ & $\ldots$ \\
\hline Did the outcome reflect the opinion of everyone? $(\mathrm{Y} / \mathrm{N})$ & 71 & 80 & $\ldots$ & $\ldots$ & 29 & 20 \\
\hline Do you want to participate in a follow-up workshop? $(\mathrm{Y} / \mathrm{N})$ & 100 & 100 & $\ldots$ & $\ldots$ & $\ldots$ & $\ldots$ \\
\hline \multicolumn{7}{|l|}{ Second workshop } \\
\hline Did you attend the first workshop? $(\mathrm{Y} / \mathrm{N})$ & 70 & 81 & $\ldots$ & $\ldots$ & 30 & 19 \\
\hline Did you feel that you could voice your opinion? $(\mathrm{Y} / \mathrm{N})$ & 100 & 100 & $\ldots$ & $\ldots$ & $\ldots$ & $\ldots$ \\
\hline Did the outcome reflect the opinion of everyone? $(\mathrm{Y} / \mathrm{R} / \mathrm{N})$ & 90 & 71 & $\ldots$ & 19 & 10 & 10 \\
\hline Do you think it would be useful to continue with such workshops? (Y/N) & 100 & 100 & $\ldots$ & $\ldots$ & $\ldots$ & $\ldots$ \\
\hline
\end{tabular}

conducted at only one scale will usually miss such differences in values and perspectives. Furthermore, in developing scenarios at different scales and to ensure that the discussion is meaningful and understandable to all, it is critical that the issues be framed from a perspective appropriate to each scale.

\section{Naming and scenario ownership}

The naming of scenarios is related to the ownership that stakeholders take of the process and the resulting scenarios. This has a direct impact on the possible effectiveness of the scenario exercise. Tables 1 and 3 list the wide range of names given to the scenarios in SAfMA and MedAction. The naming of scenarios triggered heated debates in both projects. These discussions provided insight into what different participants considered to be the main point of each scenario and how they felt the scenario impacted their interests. In MedAction, local-level names like Aquatic Change, in contrast to Convulsive Change at the European level, and Big
Is NOT Beautiful, in contrast to Big Is Beautiful, reflected the opposition of the local participants to the developments in the higher-level Mediterranean scenarios. Partly as a reaction to the top-down methodology, all local scenario names, e.g., Local Tensions, in MedAction stressed to some degree the importance of the local situation. In SAfMA, there was opposition to downscaling a regional scenario initially named NEPAD. NEPAD, the New Partnership for Africa's Development, is an ambitious political agenda for greatly enhancing development in Africa, developed and supported by African political leaders at the national scale. Although widely supported at higher governmental levels, some stakeholders at the local level felt marginalized by the process and were opposed to the idea of developing a scenario with this name or based on the NEPAD initiative. 
Table 3. Link between a selection of the scenarios developed at different scales in MedAction. Scenarios at lower levels were developed given the higher-level developments.

\begin{tabular}{ccc}
\hline \hline European/Mediterranean & Guadalentín & Val d'Agri \\
\hline Big Is Beautiful & Elimination of Middlemen & Big Is NOT Beautiful \\
Knowledge Is King & Sunbelt Formation & Local Tensions \\
Convulsive Change & Aquatic Change & Human Desertification \\
$\ldots$ & Sustainable Tourism ${ }^{\dagger}$ & Multifunctional Agriculture $^{\dagger}$ \\
\hline
\end{tabular}

${ }^{\dagger}$ Scenarios not directly linked to higher-level scenarios

\section{Multiscale application}

One of the key objectives in developing participatory scenarios is to involve policy makers and other stakeholders and thus more directly exert influence on the long-term planning process. The success of participatory scenario development should therefore ultimately be measured by the influence of the resulting scenarios. The potential long-term effects, e.g., changing attitudes and agendas (see Patel et al. 2007), are hard to measure, but both MedAction and SAfMA successfully engaged in a large number of activities to disseminate the results. The findings of SAfMA have been presented and distributed to major decision-making bodies in the region. These include the Development Bank of Southern Africa and representatives of NEPAD and the Southern African Development Community. Briefings have been requested by the National Environmental Advisory Forum of South Africa, specifically to discuss the constraints that ecosystem services impose on economic growth in the context of the accelerated growth strategy for the country. The SAfMA scenarios are also being used by the Center for Invasion Biology at the University of Stellenbosch to explore scenarios of future biological invasions in the country. Within MedAction, all the countries involved in the United Nations Convention to Combat Desertification Focal Points actively participated and were very positive about the methods and results of the project. Direct recommendations have been communicated to representatives of the European Commission, of which members were present during a large stakeholder conference at which results were discussed. Nevertheless, both projects were largely designed to initiate normative long-term changes rather than practical short-term changes. Of this there is little concrete evidence as yet.

\section{INSIGHTS: DOWNSCALING AND UPSCALING METHODS}

There is an important trade-off between standardizing the methodology across scales to allow for cross-scale comparison and analyses and maximizing the relevance to regional/local stakeholders by developing scenarios independently at different scales. In MedAction, the development of the local-level scenarios was driven by an interest in possibilities for combating desertification, as framed by the Common Agricultural Policy at the European level. Thus, the methods chosen maximized comparability across regions and favored a standardized, cross-scale methodology. In SAfMA, the aim of scenario development was to provide policy-relevant information to decision makers at each particular scale. Scenarios were therefore largely developed independently and linked afterwards across scales (see Table 1). The flow of information between scales was therefore larger in MedAction. This section draws largely on the scaling issues encountered in the MedAction project arising from the desire for a high level of cross-scale consistency. 


\section{Scaling down: blessing or burden?}

Scenarios developed within MedAction were on the whole successfully downscaled from the European level to the local watershed level. This is apparent from several observations. First, local stakeholders learned the importance of including national and European processes in their evaluation of future opportunities (see Patel et al. 2007). Second, a large number of higher-level developments were not only understood, but translated to the local situation and incorporated into the scenarios (see Kok et al. $2006 b$ ). Third, a large number of consistent and mutually comparable scenarios were developed. Finally, local stakeholders critically evaluated higher-level scenarios within their context.

Nevertheless, the following problems became apparent during the downscaling process.

\section{Loss of variety}

The experience from MedAction is that it is often not possible to maintain the variety of scenario outcomes when scenarios are downscaled. In all local cases, the majority of the participants perceived the higher-level scenarios as having mostly negative consequences for their areas. For example, contrary to the European scenarios, the agricultural sector declined in all local-level scenarios. Scenarios that result in very different outcomes at higher levels may lead to very similar outcomes in a particular region. Similarly, in SAfMA it was felt that the global-level Millennium Ecosystem Assessment scenarios called Global Orchestration and Techno Garden would play out almost identically in southern Africa, despite marked differences in other parts of the world. Adopting a strict downscaling methodology can therefore limit the possibility space explored at the local level.

\section{Temporal mismatch}

Local scenarios tend to consider a time scale of maximally one generation (15-25 yr), whereas scenarios for larger areas generally consider a time horizon of at least $50 \mathrm{yr}$. These longer time spans are necessary to capture slower processes acting over large geographical areas. In both MedAction and SAfMA, scenarios had a time frame that ranged from $15 \mathrm{yr}$ at the local level to $30 \mathrm{yr}$ at the regional level. Dealing with the temporal dimension when downscaling scenarios is far from trivial, particularly when the time scale is shortened. For example, in the MedAction Big Is Beautiful scenario, an explosively growing European Union and merger mania among multinationals result in a few enormous power blocs that fail to take social and environmental responsibility, leading to social and environmental breakdown (Fig. 3). Shortening the time horizon from 2050 to 2030 will invariably result in a different, possibly incomplete, scenario.

\section{Creative translation}

The scenarios in both projects were highly integrated, dealing with environmental, social, and economic issues that all needed to be consistent across scales. The amount of information and the way in which it is provided to stakeholders during the downscaling process present additional problems. In introducing the Mediterranean scenarios to local stakeholders in MedAction, it was stressed that the three Mediterranean scenarios simply defined possible higher-level driving forces, and that stakeholders should think creatively about scenarios for their own regions. Nevertheless, local scenarios after the first workshop were largely similar to the three Mediterranean-level scenarios. Information on general attitudes, such as "Europe is more environmentally friendly," was creatively translated into local scenarios: "ecotourism will bloom," "small-scale agriculture will prevail," "windmill parks will be built." In contrast, largescale facts, such as "tourism will grow," were directly downscaled without questioning the probability of growing tourist numbers in the specific region. The conclusion from MedAction was that local stakeholders will be less overwhelmed by global developments, particularly social and economic developments, if they are not presented as facts but rather as underlying assumptions and changes in world views.

\section{Diverging scenarios}

Because of the temporal, spatial, and contextual differences discussed above, the resulting scenarios at different scales in MedAction were consistent across scales, but often with a rather low degree of direct comparability. In other words, scenarios were consistently based on the same assumptions and consistently included the same main driving forces, but specific developments varied largely. In particular, the high degree of stakeholder input in drafting the local scenarios and the use of largely qualitative storylines resulted in the incorporation of local variability and thus diverging scenarios. 
Fig. 3. Overall ecological and societal impact with the progression of time in the MedAction Big Is Beautiful scenario. Reducing the timescale of the scenario can result in a markedly different or incomplete scenario.

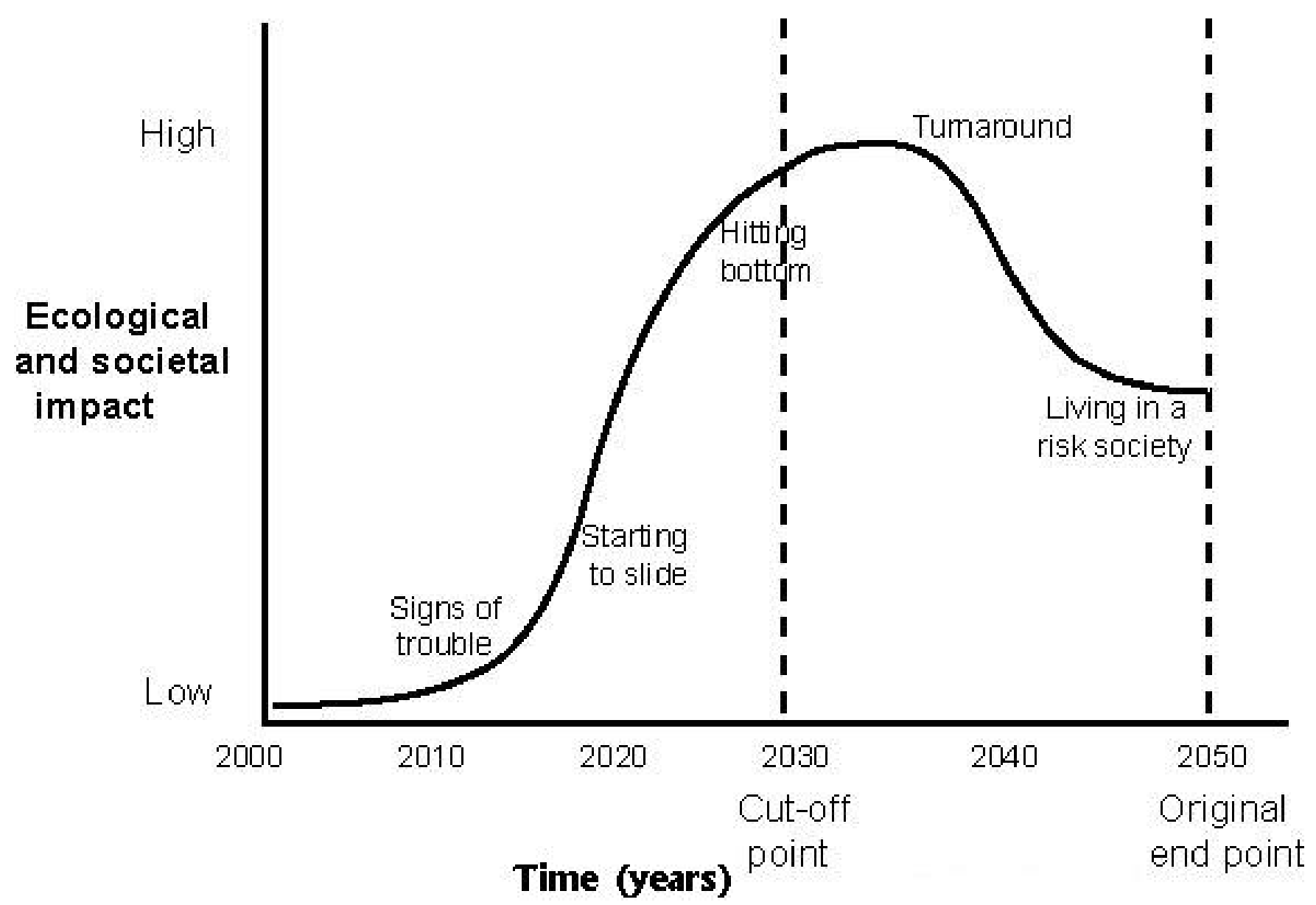

We conclude that downscaling scenarios from the continental to the local level is possible, resulting in sets of linked scenarios across scales. However, adopting a methodology that predefines the main driving forces across scales limits variability and can potentially limit stakeholders' creativity. By constructing scenarios with clear end points for every decade and by the flexible use of a higherlevel framework, creativity and ownership at lower levels can be encouraged without losing the crossscale connections. Locally important factors that might be more influential than regional-scale drivers need to be explicitly considered when a downscaling exercise is contemplated (e.g., Lebel et al. 2005). A promising method that has received relatively little attention to date is developing scenarios for one particular scale during workshops that involve stakeholders from multiple scales. This type of workshop would help ensure direct feedback between scales in the scenario development process.

Our experiences further suggest that formal downscaling of scenarios should be attempted only if there is particular scientific or policy value in maintaining direct comparability across scales, or if cross-scale drivers could have important impacts that cannot be adequately considered in a set of scenarios constructed independently at different 
scales. When the aim is solely or primarily to aid decision making at different levels, it will usually be preferable to construct the scenarios for each scale semi-independently, as was done in SAfMA (Biggs et al. 2004). Such an exercise will uncover the different perspectives and trade-offs across scales but at a substantially lower technical and political cost. In such cases, however, using a broad common framework is highly desirable, as are meetings that allow for interaction between scenario developers working at different scales.

\section{Scaling up participatory scenarios}

The MedAction experience shows that upscaling local scenarios is difficult but possible. After construction of the local-scale scenarios, a large number of scenario-specific changes were made to the three Mediterranean-level scenarios (see Kok et al. 2004) to enrich them with local-level information. Elements from the local-level scenarios directly contested some assumptions in the European scenarios. For example, in Knowledge Is King it was assumed that part of the population will voluntarily refrain from being part of the electronic age. This assumption was challenged in all the local scenarios. In Big Is Beautiful, the assumed breakdown of society was dismissed as highly unlikely. These reactions were fed back up to the Mediterranean-level scenarios and adjustments made accordingly.

MedAction also revealed that stakeholders often have a strong resistance to change. Local stakeholders viewed many of the large-scale changes that might happen as unfavorable and, when given the opportunity to construct a desirable future, they opted for as little change as possible. Although perhaps not surprising, this is an important point to keep in mind when upscaling any of the results from local participatory scenarios to a higher level. On the other hand, many local scenarios contained assumptions on increased migration flows that surpassed any of the projections in the European scenarios. Besides, it is important to keep in mind that many factors that could be upscaled were assumptions rather than facts. These assumptions were based on local-level world views and desires that differed from those of stakeholders or scientists at higher levels. For example, in the Mediterranean Knowledge Is King scenario, it is assumed that the information and communications technology sector strongly dominates and leads to a number of inventions. What could be upscaled was society's ability to invent rather than the actual inventions, which depended strongly on specific local factors. Importantly, many factors that are downscaled are similarly based on the world views and desires of higher-level stakeholders, which may often drown out those of less powerful local-level stakeholders.

\section{CONCLUSION}

The Southern Africa Millennium Ecosystem Assessment (SAfMA) and MedAction represent two examples of multiscale participatory scenarios. Despite the differing contexts in which they were developed, strong similarities emerged in the methodologies used and the lessons learned that we feel may aid further work in this area. Our experiences suggest that multiscale participatory scenarios have particular value in four areas:

- Multiscale scenario development is an excellent tool to engage stakeholders in thinking creatively about the future. This encourages a more proactive attitude to either helping shape or adapting to the future.

- Linking multiple scales introduces a greater appreciation of the interconnectivity of processes and people operating at different scales, which may have been missed in a single-scale exercise. Multiscale scenarios can be particularly important in sensitizing stakeholders at each scale to the perspective of stakeholders at other scales and broadening the range of issues considered at each scale.

- Taken away from their present-day conflicts and discussing possible futures, stakeholders developed a greater understanding for each other's point of view. Although there is no guarantee that this enlarged mutual respect will carry over to resolving current conflicts, it helps foster that possibility.

- Scenarios are products that can be understood and communicated to many people. The results of MedAction have been presented in almost the same form to local stakeholders, scientific experts, and students. Scenarios are thus an excellent vehicle for bridging knowledge systems, enhancing dialogue, and educating stakeholders. 
By discussing similarities between two independent projects implemented in very different parts of the world, we have tried to demonstrate the robustness of the overall methodology. We are confident that the insights we have described in this paper are important factors to consider in most settings in which multiscale scenarios are being developed. Although the two case studies presented here predominantly used qualitative storylines, many of the lessons learned are equally valid for quantitative studies, for instance, the temporal mismatch or the loss of variety. We wish to stress that adding multiscale models to the process will further increase financial and time demands. The variety of issues raised here should be considered a caution against attempting an even more complex and larger set of objectives. We refer to Kok and Van Delden (2004) for a more detailed discussion of this topic.

Finally, we wish to note that developing scenarios is resource intensive, particularly when the aim is a top-down, bottom-up iterative cycle. Stakeholders are typically involved in multiple workshops to ensure that the scenarios are credible and internally consistent. Both SAfMA and MedAction ran for several years and had resources to develop scenarios, yet neither fully involved stakeholders or completed a full iterative cycle of feedbacks. Although scenario planning is a powerful tool for addressing the future of complex systems, it may not be an appropriate tool in situations in which time or budgets are severely constrained. Significant resources need to be allocated to scenario development to reap the full benefits of scenario planning.

Responses to this article can be read online at:

http://www.ecologyandsociety.org/voll2/iss 1/art8/responses/

\section{LITERATURE CITED}

Alcamo, J. 2001. Scenarios as tools for international assessments. Prospects and Scenarios No. 5, Environmental Issue Report 24. European Environment Agency, Copenhagen, Denmark.

Allen, T. F. H., and T. B. Starr. 1982. Hierarchy: perspectives for ecological complexity. University of Chicago Press, Chicago, Illinois, USA.

Andersen, I.-E., and B. Jaeger. 1999. Scenario workshops and consensus conferences: towards more democratic decision-making. Science and Public Policy 26:331-340.

Antrop, M. 2000. Background concepts for integrated landscape analysis. Agriculture, Ecosystems \& Environment 77:17-28.

Biggs, R., E. Bohensky, P. V. Desanker, C. Fabricius, T. Lynam, A. A. Misslehorn, C. Musvoto, M. Mutale, B. Reyers, R. J. Scholes, S. Shikongo, and A. S. van Jaarsveld. 2004. Nature supporting people: the Southern African millennium ecosystem assessment. Council for Scientific and Industrial Research (CSIR), Pretoria, South Africa.

Biggs, R., C. Raudsepp-Hearne, C. AtkinsonPalombo, E. Bohensky, E. Boyd, G. Cundill, H. Fox, S. Ingram, K. Kok, S. Spehar, M. Tengö, D. Timmer, and M. Zurek. 2007. Linking futures across scales: a dialog on multiscale scenarios. Ecology and Society 12, in press.

Bohensky, E., B. Reyers, A. S. van Jaarsveld, and C. Fabricius, editors. 2004. Ecosystem services in the Gariep Basin. SUNPReSS, Stellenbosch, South Africa.

Bohensky, E., B. Reyers, and A. S. van Jaarsveld. 2006. Future ecosystem services in a southern African river basin: a scenario planning approach to uncertainty. Conservation Biology 20(4):1051-1061.

Easterling, W. E., and K. Kok. 2003. Emergent properties of scale in global environmental modeling: Are there any? Pages 263-292 in J. Rotmans and D. S. Rothman, editors. Scaling in integrated assessment. Swets \& Zeitlinger, Lisse, The Netherlands.

European Environment Agency (EEA). 2006. PRospective Environmental analysis of Land Use Development in Europe (PRELUDE). Land use scenarios for Europe-modeling at the European scale. Background report. EEA, Copenhagen, Denmark.

Galer, G. 2004. Scenarios of change in South Africa. The Round Table 93(375):369-383.

Gallopín, G., A. Hammond, P. Raskin, and R. J. Swart. 1997. Branch points: global scenarios and human choice. Stockholm Environment Institute, Stockholm, Sweden. 
Global Land Project (GLP). 2005. Science plan and implementation strategy. International GeosphereBiosphere Programme (IGBP) Report No. 53/ International Human Dimensions Programme (IHDP) Report No. 19. IGBP Secretariat, Stockholm, Sweden.

Hisschemöller, M., and A. P. J. Mol, editors. 2002. Evaluating the COOL dialogues. Climate OptiOns for the Long Term-final report, Volume E. Institute for Environmental Studies, Free University of Amsterdam, Amsterdam, The Netherlands.

Hughes, B. B. 1999. International futures: choices in the search for a new world order. Westview Press, Boulder, Colorado, USA.

Intergovernmental Panel on Climate Change (IPCC). 2002. Special report on emissions scenarios (SERS). Available online at: http://www. grida.no/climate/ipcc/emission/index.htm.

Kahane,A. 1998. Changing the winds. Whole Earth 96:77-81.

Kahn, H., and A. Weiner. 1967. The year 2000: $a$ framework for speculation on the next thirty-three years. Macmillan, New York, New York, USA.

Kok, K., and H. van Delden. 2004. Linking narrative storylines and quantitative models to combat desertification in the Guadalentín, Spain. Pages 754-759 in Proceedings of the Second Biennial Meeting of the International Environmental Modelling and Software Society (iEMSs) (Osnabrück, 2004). iEMSs, Manno, Switzerland.

Kok, K., M. Patel, and D. S. Rothman. 2004. Final report of European and Mediterranean scenarios: upscaling the results from the target area scenarios. MedAction Deliverable 4. International Centre for Integrated assessment and Sustainable development (ISIS) working paper I04-E002. Maastricht University, Maastricht, The Netherlands. Available online at: http://www.icis.unimaas.nl/medaction.

Kok, K., D. S. Rothman, and M. Patel. $2006 a$. Multiscale narratives from an IA perspective. Part 1. European and Mediterranean scenario development. Futures 38:285-311.

Kok, K., M. Patel, D. S. Rothman, and G. Quaranta. 2006b. Multiscale narratives from an IA perspective. Part 2. Participatory local scenario development. Futures 38:261-284.

Lebel, L., P. Thongbai, K. Kok, J. B. R. Agard, E. Bennett, R. Biggs, M. Ferreira, C. Filer, Y. Gokhale, W. Mala, C. Rumsey, S. J. Velarde, Monika Zurek, H. Blanco, T. Lynam, Y. Tianxiang. 2005. subglobal scenarios. Pages 227-258 in D. Capistrano, C. K. Samper, M. J. Lee, and C. Raudsepp-Hearne, editors. Ecosystems and human well-being volume 4: multiscale assessments. Findings of the subglobal assessments working group of the Millennium Ecosystem Assessment. Island Press, Washington, D.C., USA.

Lynam, T., A. Sitoe, B. Reichelt, R. Owen, R. Zolho, R. Cunliffe, and I. Bwerinofa. 2004. Human well-being and ecosystem services: an assessment of their linkages in the GorongosaMarromeu region of Sofala Province, Mozambique to 2015. Institute of Environmental Studies, University of Zimbabwe, Harare, Zimbabwe.

Millennium Ecosystem Assessment (MA). 2003. Ecosystems and human well-being: a frameworkfor assessment. Island Press, Washington, D.C., USA.

Millennium Ecosystem Assessment (MA). 2005. Ecosystems and human well-being: scenarios: findings of the scenarios working group. Island Press, Washington, D.C., USA. Available online at: http://www.maweb.org/en/Scenarios.aspx.

New Partnership for Africa's Development (NEPAD). 2001. The new partnership for Africa's development (NEPAD). Available online at: www.n epad.org/2005/files/documents/inbrief.pdf.

New Partnership for Africa's Development (NEPAD). 2005. Summary of NEPAD action plans. Available online at: http://www.nepad.org/2005/files/ documents/41.pdf.

O'Neil, R. V. 1988. Hierarchy theory and global change. Pages 29-25 in T. Roswall, R. G. Woodmansee, and P. G. Risser, editors. SCOPE 35 -scales and global change. John Wiley, Chichester, UK.

Patel, M., K. Kok, and D. S. Rothman. 2007. Participatory planning in land use analysis: an insight into the experiences and opportunities created by stakeholder involvement in scenario construction in the Northern Mediterranean. Land Use Policy 24, in press. 
Peterson, D. L., and V. T. Parker, editors. 1998. Ecological scale: theory and applications. Columbia University Press, New York, New York, USA.

Peterson, G. D., G. S. Cumming, and S. R. Carpenter. 2003. Scenario planning: a tool for conservation in an uncertain world. Conservation Biology 17:358-366.

Raskin, P., G. Gallopín, P. Gutman, A. Hammond, and R. Swart. 1998. Bending the curve: toward global sustainability. PoleStar Series Report No. 8 of the Global Scenario Group, Stockholm Environment Institute, Stockholm, Sweden.

Raskin, P., T. Banuri, G. Gallopín, P. Gutman, A. Hammond, R. W. Kates, and R. J. Swart. 2002. Great transition: the promise and lure of times ahead. Stockholm Environment Institute, Boston, Massachusetts, USA.

Raskin, P., F. Monks, T. Ribeiro, D. van Vuuren, and M. Zurek. 2005. Global scenarios in historical perspective. Pages 35-44 in S. R. Carpenter, P. L. Pingali, E. M. Bennett, and M. B. Zurek, editors. Ecosystems and human well-being: scenarios. Volume 2: findings of the scenarios working group of the Millennium Ecosystem Assessment. Island Press, Washington, D.C., USA. Available online at: http://www.maweb.org/documents/document.326.aspx. pdf.

Rotmans, J., M. B. A. van Asselt, C. Anastasi, S. C. H. Greeuw, J. Mellors, S. Peters, D. S. Rothman, and N. Rijkens-Klomp. 2000. Visions for a sustainable Europe. Futures 32:809-831.

Rotmans, J., and D. S. Rothman, editors. 2003. Scaling in integrated assessment. Swets \& Zeitlinger, Lisse, The Netherlands. QUERIED

Rounsevell, M. D. A., F. Ewert, I. Reginster, R. Leemans, and T. R. Carter. 2005. Future scenarios of European agricultural land use 2: projecting changes in cropland and grassland. Agriculture, Ecosystems \& Environment 107:117-135.

Scholes, R. J., and R. Biggs. 2004. Ecosystem services in southern Africa: a regional assessment. Council for Scientific and Industrial Research (CSIR), Pretoria, South Africa.
Schwartz, P. 1991. The art of the long view: paths to strategic insight for yourself and your company. Doubleday, New York, New York, USA.

United Nations Environment Programme (UNEP). 2002. Global environment outlook 3. UNEP, Nairobi, Kenya.

Van Asselt, M. B. A., and N. Rijkens-Klomp. 2002. A look in the mirror: reflection on participation in integrated assessment from a methodological perspective. Global Environmental Change 12:167-184.

Van Asselt, M. B. A., J. Rotmans, and D. S. Rothman, editors. 2005. Scenario innovation: experiences from a European experimental garden. Taylor \& Francis, Leiden, The Netherlands.

Van Notten, P. W. F., J. Rotmans, M. B. A. van Asselt, and D. S. Rothman. 2003. An updated scenario typology. Futures 35:423-443.

Wack, P. 1985. Scenarios: shooting the rapids. Harvard Business Review 63:139-150.

Walker, B. H., L. H. Gunderson, A. P. Kinzig, C. Folke, S. R. Carpenter, and L. Schultz. 2006. A handful of heuristics and some propositions for understanding resilience in social-ecological systems. Ecology and Society 11: 13. [online] URL: http://www.ecologyandsociety.org/vol11/iss1/art13/

Westhoek, H. J., M. van den Berg, and J. A. Bakkes. 2006. Scenario development to explore the future of Europe's rural areas. Agriculture, Ecosystems \& Environment 114:7-20.

Wollenberg, E., D. Edmunds, and L. Buck. 2000. Using scenarios to make decisions about the future: anticipatory learning for the adaptive comanagement of community forests. Landscape and Urban Planning 47:65-77. 